\title{
Structural basis for supercooled liquid fragility established by synchrotron-radiation method and computer simulation
}

\author{
D. V. Louzguine-Luzgin, ${ }^{1, a)}$ R. Belosludov, ${ }^{2}$ A. R. Yavari, ${ }^{1,3,4}$ K. Georgarakis,,${ }^{1,3}$ \\ G. Vaughan, ${ }^{4}$ Y. Kawazoe, ${ }^{2}$ T. Egami, ${ }^{5,6,1}$ and A. Inoue ${ }^{1}$ \\ ${ }^{1}$ WPI Advanced Institute for Materials Research, Tohoku University, Aoba-Ku, Sendai 980-8577, Japan \\ ${ }^{2}$ Institute for Materials Research, Tohoku University, Aoba-Ku, Sendai 980-8577, Japan \\ ${ }^{3}$ SIMAP-LTPCM, Institut National Polytechnique de Grenoble, St-Martin-d'Hères Campus, Grenoble, \\ BP 75, 38402, France \\ ${ }^{4}$ European Synchrotron Radiation Facility, 38042, Grenoble, France \\ ${ }^{5}$ Joint Institute for Neutron Sciences, Department of Materials Science and Engineering \\ and Department of Physics and Astronomy, University of Tennessee, Knoxville, Tennessee 37996, USA \\ ${ }^{6}$ Oak Ridge National Laboratory, Oak Ridge, Tennessee 37831, USA
}

Metallic melts above the liquidus temperature exhibit nearly Arrhenius-type temperature dependence of viscosity. On cooling below the equilibrium liquidus temperature metallic melts exhibit a non-Arrhenius temperature dependence of viscosity characterized by liquid fragility phenomenon which origin is still not well understood. Structural changes and vitrification of the $\mathrm{Pd}_{42.5} \mathrm{Cu}_{30} \mathrm{Ni}_{7.5} \mathrm{P}_{20}$ liquid alloy on cooling from above the equilibrium liquidus temperature are studied by synchrotron radiation X-ray diffraction and compared with the results of first-principles calculations. Subsequent analysis of the atomic and electronic structure of the alloy in liquid and glassy states reveals formation of chemical short-range order in the temperature range corresponding to such a non-Arrhenius behavior. The first-principles calculations were applied to confirm the experimental findings.

\section{INTRODUCTION}

Metallic melts above liquidus temperature show nearly Arrhenius-type temperature dependency of viscosity. On cooling below the equilibrium liquidus temperature they exhibit a rapid rise in viscosity and non-Arrhenius temperature dependence of viscosity characterized by the fragility of the liquid. ${ }^{1}$ The origin of fragility of glass-forming liquids is being actively studied at present. ${ }^{2,3}$ Covalent silicate glasses have a network structure which is stable within the supercooled liquid. Metallic glasses in general possess non-directional metallic bonds character, and thus, may exhibit rapid changes in the atomic order in the supercooled liquid state which, however, has not been clearly demonstrated yet for metallic glasses partly because of their relatively low stability against crystallization.

High glass-forming ability (GFA) achieved for some alloy compositions allowed production of bulk metallic glasses in the thickness range of $1-100 \mathrm{~mm}$ using various casting processes. ${ }^{4-6}$ When subjected to flux treatment $\mathrm{Pd}-\mathrm{Ni}$ P (Ref. 7), Pd-Ni-Cu-P bulk metallic glasses (Ref. 8 and 9) and Pd-Ni-P-Si (Ref. 10) are among the best metallic glassformers known to date. The structures of $\mathrm{Pd}-\mathrm{Ni}-\mathrm{P}^{11}$, and $\mathrm{Pd}$ Ni-Cu-P glasses ${ }^{12}$, in particular $\mathrm{Pd}_{42.5} \mathrm{Ni}_{7.5} \mathrm{Cu}_{30} \mathrm{P}_{20}$ (Ref. 13), have been studied by X-ray diffraction (XRD) and transmission electron microscopy (TEM). Thermal behavior of $\mathrm{Pd}_{40} \mathrm{Cu}_{30} \mathrm{Ni}_{10} \mathrm{P}_{20}$ alloy ${ }^{14}$ was studied though vitrification

\footnotetext{
a) Author to whom correspondence should be addressed. Electronic mail: dml@wpi-aimr.tohoku.ac.jp.
}

under the beam was not possible, because of crystallization on relatively slow cooling. ${ }^{15}$ Such an experiment is possible on oxides ${ }^{16}$ which owing to significantly higher GFA were slowly cooled. Structural changes, thermal expansion and volume changes (structural relaxation) upon heating have been studied by synchrotron X-ray radiation diffraction in Pd-, Zr-, ${ }^{17,18} \mathrm{La}^{19}$ as well as Cu-based glassy alloys. ${ }^{20} \mathrm{It}$ was also found that the medium-range order in metallic glasses $^{21}$ spans up to about 1-2 nm (Refs. 22 and 23).

In the present work we study structural changes in the relatively fragile $\mathrm{Pd}_{42.5} \mathrm{Cu}_{30} \mathrm{Ni}_{7.5} \mathrm{P}_{20}$ melt [its fragility index $m$ (Ref. 24) is close to 60 (Ref. 25)] during cooling by using the real-space pair distribution function (PDF) [which is a reduced form of radial distribution function (RDF)] and compare the results to those obtained by the first-principles computer simulation. We report detection of anomalies in the evolution of the atomic structure in the supercooled liquid region that appear to be directly connected to the fragility (temperature dependence of viscosity) of this liquid alloy.

\section{EXPERIMENTAL PROCEDURE}

An ingot of $\mathrm{Pd}_{42.5} \mathrm{Cu}_{30} \mathrm{Ni}_{7.5} \mathrm{P}_{20}$ alloy (the composition is given in nominal atomic percentage) was prepared from pure metals of 99.9 mass\% purity and a Pd-P master alloy using arc-melting method, and then subjected to a fluxing treatment with $\mathrm{B}_{2} \mathrm{O}_{3}$ in order to eliminate impurities that can act as heterogeneous nucleation sites for crystallization. Bulk samples were produced from the fluxed ingots by copper mold casting and encapsulated under secondary vacuum (of 
the order of $1 \times 10^{-3} \mathrm{~Pa}$ ) in a quartz container of $5 \mathrm{~mm}$ inner diameter.

In situ X-ray diffraction measurements in transmission were carried out using high energy monochromatic X-ray at the European Synchrotron Radiation Facility (ESRF). A photon energy of $92.5 \mathrm{keV}$ corresponding to an X-ray wavelength of $\lambda=0.0134 \mathrm{~nm}$ was used. The samples held in a glass container were heated by an induction heater to a temperature of $910 \mathrm{~K}$, which is well above the liquidus temperature and cooled down to room temperature with flowing $\mathrm{N}_{2}$ gas being used as coolant, while the temperature was monitored by a pyrometer. Such a measurement was repeated several times for the reliability. The diffracted intensity was recorded by a two-dimensional charge coupled device (CCD) camera and the acquisition time was two second per spectrum. Finally, the radial intensities were integrated over 360 degrees to enhance signal to noise ration.

One should mention that only quaternary $\mathrm{Pd}_{42.5} \mathrm{Cu}_{30}$ $\mathrm{Ni}_{7.5} \mathrm{P}_{20}$ alloy vitrified on cooling under the $\mathrm{X}$-ray beam owing to its high glass-forming ability. Similar method has been applied in Ref. 17. Other alloys were also preliminary tested. However, a binary $\mathrm{Pd}_{81} \mathrm{Si}_{19}$ alloy crystallized on cooling. Zr-based alloys were also tested but no in situ vitrification was achieved.

After necessary corrections the measured intensity was converted to electron units per atom with the generalized Krogh-Moe-Norman method. ${ }^{26,27}$ Density value of 9.215 $\mathrm{Mg} / \mathrm{m}^{3}$ for the alloy was taken from Ref. 28. The total structure factor $\mathrm{S}(\mathrm{Q})$ and the interference function $\mathrm{Qi}(\mathrm{Q})$ $(\mathrm{Q}=4 \pi \sin \theta / \lambda, \theta$ is the diffraction angle) were obtained from the coherent scattering intensity by using atomic scattering factors. The values of $\mathrm{Qi}(\mathrm{Q})$ at $\mathrm{Q}$ less than $18 \mathrm{~nm}^{-1}$ were smoothly extrapolated to zero. The radial distribution $\mathrm{RDF}(\mathrm{R})$ and pair distribution functions $\operatorname{PDF}(\mathrm{R})$ were obtained by the Fourier transform of Qi $(\mathrm{Q})^{26}$

$$
\begin{aligned}
\mathrm{RDF}(\mathrm{R}) & =4 \pi \mathrm{r}^{2} \rho(\mathrm{R}) \\
& =4 \pi \mathrm{R}^{2} \rho_{0}+2 \mathrm{R} / \pi \int_{0}^{\mathrm{Qmax}} \mathrm{Qi}(\mathrm{Q}) \sin (\mathrm{Q} \bullet \mathrm{R}) \mathrm{dQ}
\end{aligned}
$$

where $\rho(\mathrm{R})$ is the total radial number density function and $\rho_{0}$ is the average number density of the sample. $\operatorname{PDF}(\mathrm{R})$ $=R D F(R)-4 \pi \mathrm{R}^{2} \rho_{0}$ is a reduced function.

The atomic structures of $\mathrm{Pd}_{42.5} \mathrm{Cu}_{30} \mathrm{Ni}_{7.5} \mathrm{P}_{20}$ alloy in both liquid and glassy states have been also investigated using the first-principles calculations. The calculations are performed using density functional theory based pseudopotential plane-wave method as implemented in VASP code. ${ }^{29,30}$ The spin polarized generalized gradient corrected Perdew-Burke-Ernzerhof exchange-correlation functional ${ }^{31}$ and the all-electron projector augmented wave method ${ }^{32}$ were used in order to accurately describe the interaction between the ion and electron. The $\mathrm{Pd}_{42.5} \mathrm{Cu}_{30} \mathrm{Ni}_{7.5} \mathrm{P}_{20}$ configuration was modeled within a cubic supercell consisting of 240 atoms. At the first step, the random atomic structure with density $\left(8.66 \mathrm{~g} / \mathrm{cm}^{3}\right)$ was melted at $2000 \mathrm{~K}$ for a total of 2000 steps with each step time of 5 fs. After that, the obtained system in liquid state was additionally equilibrated for $5 \mathrm{ps}$ at $950 \mathrm{~K}$ and then was quenched to $550 \mathrm{~K}$ with a cooling rate of $4 \times 10^{13} \mathrm{~K} / \mathrm{s}$ at 500 time steps per $100 \mathrm{~K}$. The final configuration was additionally optimized with experimentally reported density of glassy states $\left(9.215 \mathrm{~g} / \mathrm{cm}^{3}\right)$ using a conjugated gradient method. The Brillouin zone integrations are carried out using only the $\Gamma$-point.

\section{RESULTS}

After heating above $900 \mathrm{~K}$ (liquidus $\mathrm{T}_{1}$ is at around $800 \mathrm{~K}$ ) the sample was cooled at about $8 \mathrm{~K} / \mathrm{s}$ (average cooling rate) down to room temperature $(298 \mathrm{~K})$ and the sample vitrified. The interference function $\mathrm{Qi}(\mathrm{Q})$ for liquid alloy at $873 \mathrm{~K}$ calculated from the diffraction intensity profile after the necessary corrections is shown in Fig. 1.

An PDF(R) obtained by the Fourier Transform of Qi(Q) at $873 \mathrm{~K}$, for example, is also shown in Fig. 1. The plots of the first coordination shell of two typical atomic pair distribution functions $\operatorname{PDF}(\mathrm{R})$ are shown in Fig. 2. A sub-peak at low R (P1) of about $0.224 \mathrm{~nm}$ (at $298 \mathrm{~K}$ ) is clearly visible on the first PDF (R) nearest neighbor $(\mathrm{NN})$ peak.

Fitting of this first $\mathrm{PDF}(\mathrm{R})$ maximum from 0.2 to 0.35 $\mathrm{nm}$ (baseline was corrected to make both outermost points be equal to zero) using 2 Gaussian peak functions produced a reasonable correspondence with the original $\operatorname{PDF}(\mathrm{R})$ plot (Fig. 2). According to the interatomic distances corresponding to sums of atomic radii $\mathrm{r}_{\mathrm{Pd}}=0.138 \mathrm{~nm} \mathrm{r} \mathrm{ru}_{\mathrm{Cu}}=0.128 \mathrm{~nm}$, $\mathrm{r}_{\mathrm{Ni}}=0.125 \mathrm{~nm}$ and $\mathrm{r}_{\mathrm{P}}=0.106 \mathrm{~nm}^{33}$ at room temperature the first subpeak (P1) at $0.224 \mathrm{~nm}$ corresponds to nearest $\mathrm{Cu}-\mathrm{P}$ or Ni-P atomic pairs while the second subpeak at $0.274 \mathrm{~nm}$ (P2) mostly corresponds to the mixture of $\mathrm{Pd}-\mathrm{Pd}, \mathrm{Pd}-\mathrm{Cu}$ and Pd-Ni pairs. The Pd-P distance has an intermediate position. Other possible sub-peaks were not resolved owing to limited resolution of the method connected with Fourier Transform truncation error.

Error sources in XRD measurements and data analysis have been discussed in Ref. 34. In order to perform error analysis four different spectra were obtained at $873 \mathrm{~K}$ which

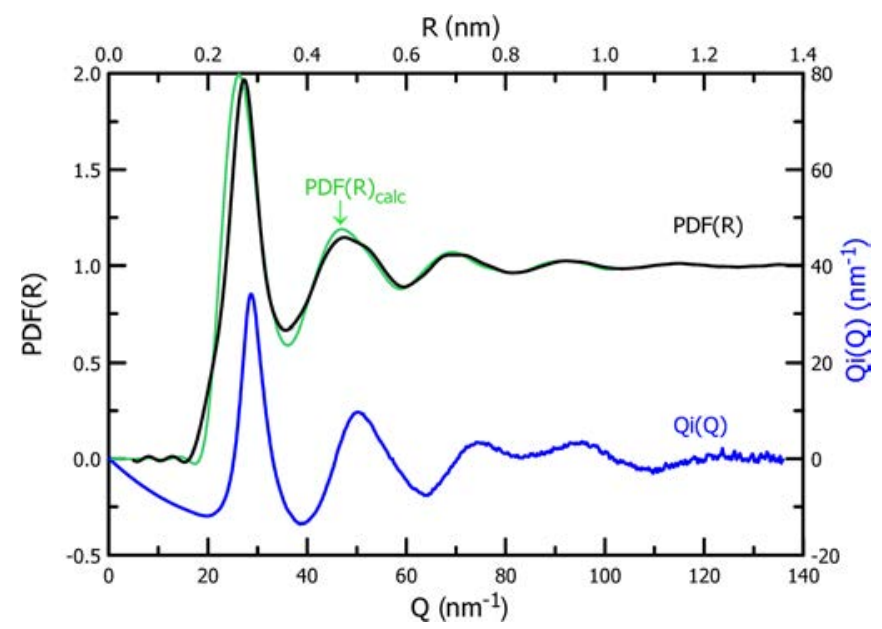

FIG. 1. (Color online) The interference function Qi(Q) for the studied alloy at $873 \mathrm{~K}$ calculated from the XRD intensity profile after the necessary corrections, experimental $\mathrm{PDF}(\mathrm{R})$ derived at a temperature of $873 \mathrm{~K}$ and $\mathrm{PDF}(\mathrm{R})_{\text {calc }}$ as a result of computer simulation at $950 \mathrm{~K}$. 

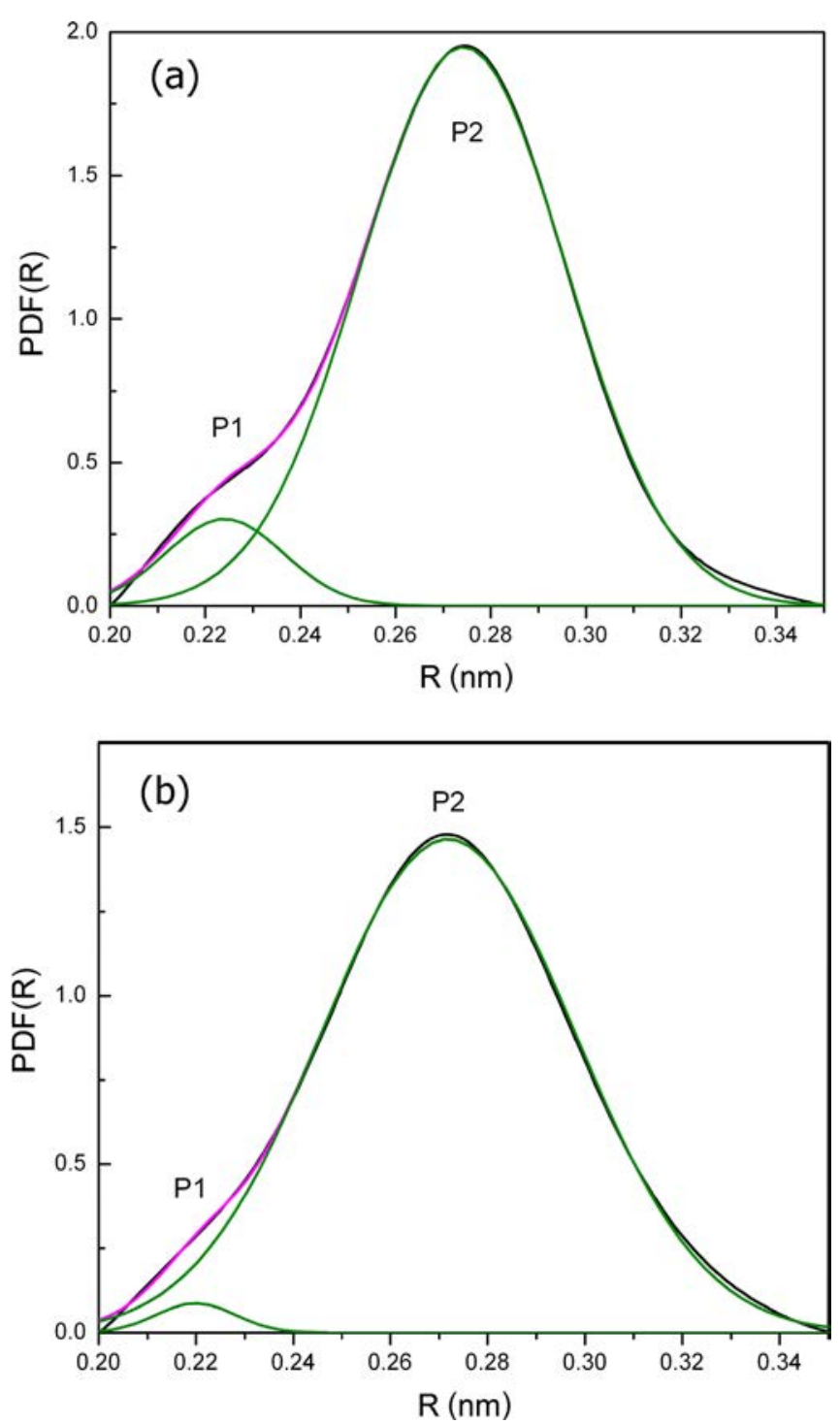

FIG. 2. (Color online) Fitting of the first PDF(R) maximum (black curve) from 0.2 to $0.35 \mathrm{~nm}$ using two Gaussian functions related to P1 (left) and P2 (right). The curves in panel (a) correspond to $298 \mathrm{~K}$ while the curves in panel (b) to $873 \mathrm{~K}$. The baseline was corrected prior to fitting.

derived very similar $\operatorname{PDF}(\mathrm{R})$ functions with two average values of the areas under subpeaks P1 and P2 of $0.001768 \pm 0.0002761$ and $0.097105 \pm 0.0014735$, respectively. Average subpeaks $\mathrm{P} 1$ and $\mathrm{P} 2$ positions are $0.2193 \pm 8.6^{*} 10^{-4}$ and $0.2718 \pm 2.39 * 10^{-5}$, respectively. The confidence intervals obtained correspond to the probability $\mathrm{P}=0.95 \%$. Cooling rate was found to be about $500 \mathrm{~K} / \mathrm{min}$ $(8.3 \mathrm{~K} / \mathrm{s})$ which being multiplied by $2 \mathrm{~s}$ acquisition time gives uncertainty of about $17 \mathrm{~K}$ per step.

With decrease in temperature the integrated area under P2 changes slightly while that under P1 increases significantly. Thus, the relative integrated intensity of a low-R subpeak of the $1^{\text {st }}$ coordination shell in the PDF becomes five times stronger on cooling from the melt to $\mathrm{T}_{\mathrm{g}}$. It indicates that the number of $\mathrm{Ni}-\mathrm{P}$ and $\mathrm{Cu}-\mathrm{P}$ atomic pairs, thus chemical short range order (CSRO) around $P$, increases on cooling the melt and then remains nearly constant in the glassy state. Absence of structural changes below $\mathrm{T}_{\mathrm{g}}$ after completion of structural relaxation was also shown earlier for $\mathrm{Cu}$-based
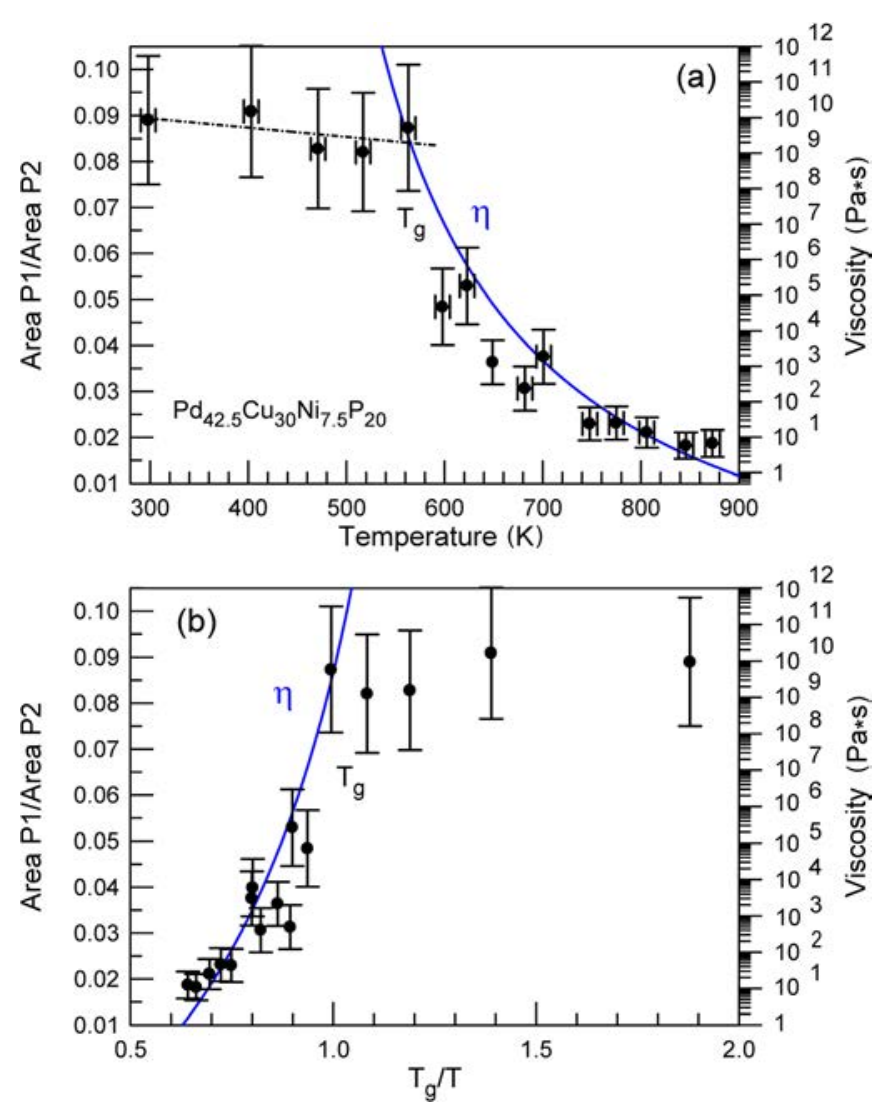

FIG. 3. (Color online) Area under P1 divided by the area under P2 in the first coordination shell obtained on cooling (solid circles) as well as viscosity of the studied alloy (blue solid line) as a function of temperature (a) and normalized inverse temperature (b).

sample. ${ }^{35}$ Figure 3 shows the area under subpeak P1 divided by the area under subpeak P2 obtained on cooling. A drastic change in this ratio above $\mathrm{T}_{\mathrm{g}}$ is demonstrated in Fig. 3.

Of course, $\mathrm{Pd}-\mathrm{P}(0.244 \mathrm{~nm}) \mathrm{Ni}-\mathrm{Ni}(0.250 \mathrm{~nm})$ and $\mathrm{Cu}-$ $\mathrm{Cu}(0.256 \mathrm{~nm})$ atomic pairs must be taken into account as these atomic pairs also shall be presented in the $\operatorname{PDF}(\mathrm{R})$ curve in Fig. 2. According to Fig. 2 these atomic interactions rather contribute to the second sub-peak P2. Also, owing to well known truncation error during fourier transform procedure the first maximum of $\operatorname{PDF}(\mathrm{R})$ becomes closer to sinusoidal function ${ }^{36,37}$ and such peaks cannot be resolved. However, as spectra obtained at each temperature have passed the same transformation procedure one can conclude that the observed changes in the intensity of the peaks represent realistic structure changes in the liquid phase on cooling.

In order to investigate the difference in the shape of the first maximum corresponding to the $\mathrm{NN}$ shell between liquid and glassy states, we carried out extensive first-principles calculations. The calculated PDFs (Fig. 4) are similar to those obtained from the experimental data (Fig. 1) and also indicate intensification of the first subpeak compared to the second one on cooling. Two $\mathrm{PDF}(\mathrm{R})$ functions obtained by computer simulation at $550 \mathrm{~K}$ (glass) and 950K (liquid) were fitted with two gaussian functions. The areas (A) under P1 and $\mathrm{P} 2$ are 0.071 and 0.051 for $550 \mathrm{~K}$ as well as 0.050 and 0.047 for $950 \mathrm{~K}$, respectively. Thus, the ratios AP1/AP2 for 

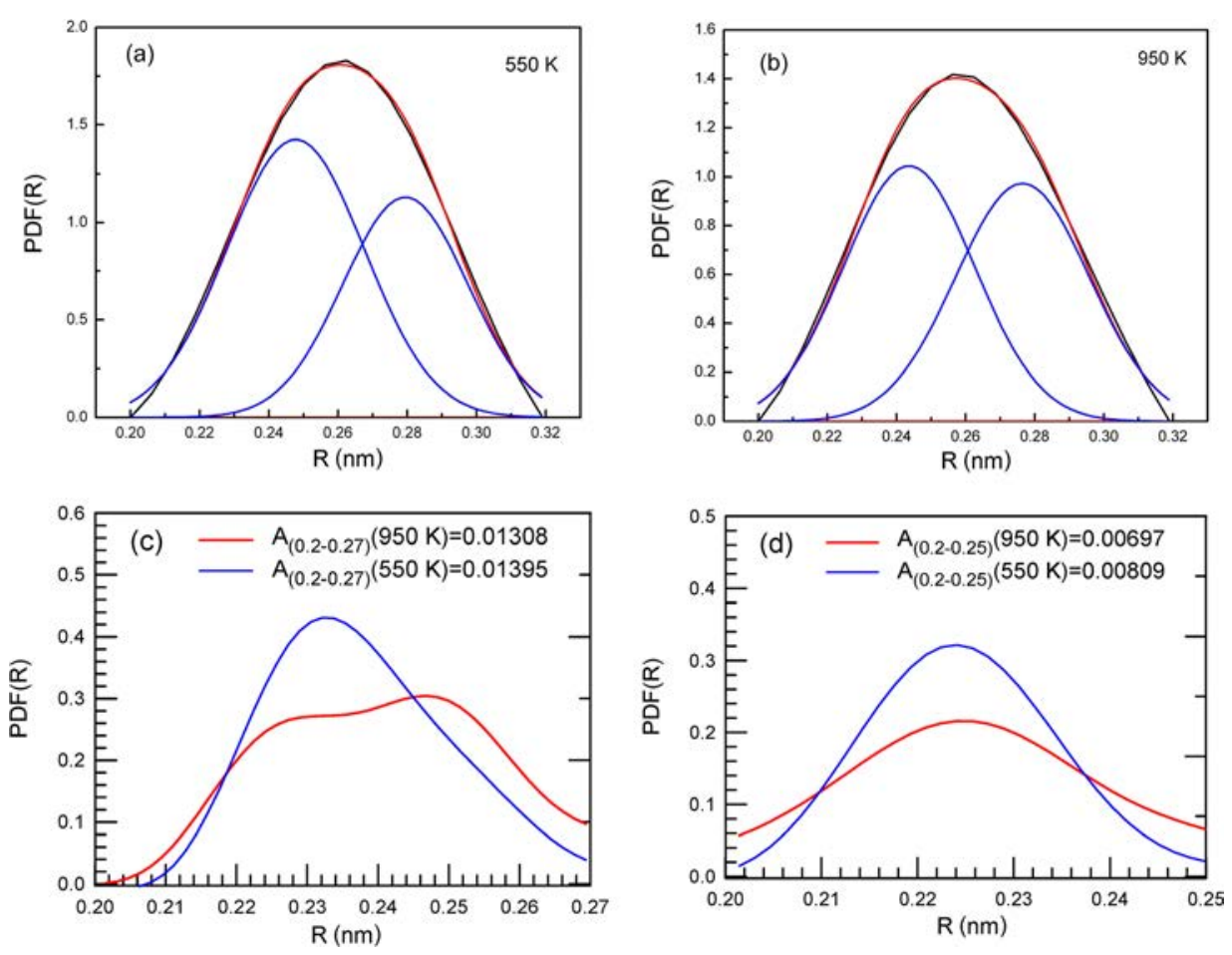

FIG. 4. (Color online) (a) Two PDF(R) functions obtained by computer simulation at $550 \mathrm{~K}$ (glass) and $950 \mathrm{~K}$ (liquid) and those fitting with two gaussian functions. Partial PDF(R) functions (c) $\mathrm{Cu}-\mathrm{P}$ and (d) Ni-P obtained by computer simulation at $950 \mathrm{~K}$ (liquid) and $550 \mathrm{~K}$ (glass). The areas (A) under the curves in the plotted range.
550 and $950 \mathrm{~K}$ are 1.38 and 1.05. Thus, these results support intensification of $\mathrm{Ni}, \mathrm{Cu}-\mathrm{P}$ peak on cooling.

One can see that experimental $\mathrm{PDF}(\mathrm{R})$ shows much lower number of $\mathrm{Ni}, \mathrm{Cu}-\mathrm{P}$ bonds than those from the curves obtained by computer simulation. This is a natural deficiency of X-ray diffraction technique as atoms with different atomic scattering factors give a different contribution to the $\mathrm{PDF}(\mathrm{R})$. X-rays are scattered by an electron cloud of an atom and hence the scattering amplitude increases with the atomic number. Thus, Pd having much larger atomic number compared to $\mathrm{Ni}$ and $\mathrm{Cu}$ thus produces stronger peaks.

Partial PDF(R) for the Ni-P and $\mathrm{Cu}-\mathrm{P}$ atomic pairs also indicate an increase in the number of such atomic bonds on cooling which is in agreement with the experimental results. The Ni-P and $\mathrm{Cu}-\mathrm{P}$ peaks intensify on cooling as illustrated by the areas (A) under the peaks at two different temperatures as shown in Figs. 4(c) and 4(d).

Moreover, as shown in Fig. 5, the calculated partial densities of states (PDOS) projected on the $3 p$ state of $P$ atoms and the $3 d$ and $4 d$ states of $\mathrm{Ni}, \mathrm{Cu}$ and $\mathrm{Pd}$ atoms, respectively, show noticeable changes in the electronic structures of $\mathrm{Pd}_{42.5} \mathrm{Cu}_{30} \mathrm{Ni}_{7.5} \mathrm{P}_{20}$ compositions toward a chemical shortrange order formation in glassy states. In the case of liquid the higher intensity of electron density below the Fermi level corresponding to metal atoms is observed. The significant reduction of the peak intensities for metal atoms in this energy region is found during the glass formation [see Fig. 5 (b)]. In contrast, the electron density of $3 p$ state of phosphorus atoms increased below Fermi level that indicates the formation of chemical bonds with $p$ - $d$ hybridization between $P$ and metal atoms due to charge transfer from metal to phosphorous. The most significant changes are found in the region between $-1.0 \mathrm{eV}$ and $-0.3 \mathrm{eV}$. In this region the largest electron density reduction of $3 d$ state are observed for $\mathrm{Ni}$ atoms and hence indicated the formation of additional $\mathrm{Ni}$ $\mathrm{P}$ bonds in the first coordination shell of $P$ atoms in center. The same tendency of $3 d$ state is also observed for $\mathrm{Cu}$ atoms but with less intensity reduction.

\section{DISCUSSION}

It is interesting to note that the temperature dependency of the viscosity plot in the logarithmic scale calculated from the data presented in Ref. 38 and superimposed on the graph (Fig. 3) shows a strong similarity to the $\mathrm{P} 1 / \mathrm{P} 2$ ratio. The temperature dependence of the viscosity of the liquid alloy was calculated using values of $\eta_{0}=5.010^{-6} \mathrm{~Pa}^{*} \mathrm{~s}, \mathrm{D}=16.5$ and $\mathrm{T}_{0}=379 \mathrm{~K}$, for the Vogel-Fulcher-Tammann (VFT) equation $^{39}$,

$$
\eta=\eta_{0} \exp \left[D^{*} T_{0} /\left(T-T_{0}\right)\right]
$$

The rapid rise of viscosity when temperature rises toward $\mathrm{T}_{\mathrm{g}}$ in the Angell plot ${ }^{40}$ is indicative of the fragility of the liquid. The coincidence of the P1/P2 ratio and $\log \eta$ as shown in Fig. 3 suggests a possibility that the rapid rise in $\mathrm{P} 1 / \mathrm{P} 2$ ratio, thus the increase in $(\mathrm{Cu}, \mathrm{Ni})-\mathrm{P}$ pairs, is closely associated with the fragile behavior of this liquid. $\mathrm{Ni}$ and $\mathrm{Cu}$ form strong covalent bond with $P$ through the $p$ - $d$ hybridization, ${ }^{41}$ and form clusters often of the topology of capped trigonal prism. ${ }^{42,43}$ Because of the strong covalent bond the local glass transition temperature of $(\mathrm{Cu}, \mathrm{Ni})-\mathrm{P}$ cluster must be quite high. ${ }^{44}$ The result shown in Fig. 3 is consistent with the possibility that increased CSRO due to formation of such clusters with decreasing temperature is contributing to the rapid increase in viscosity and results in the fragile behavior of this liquid. 

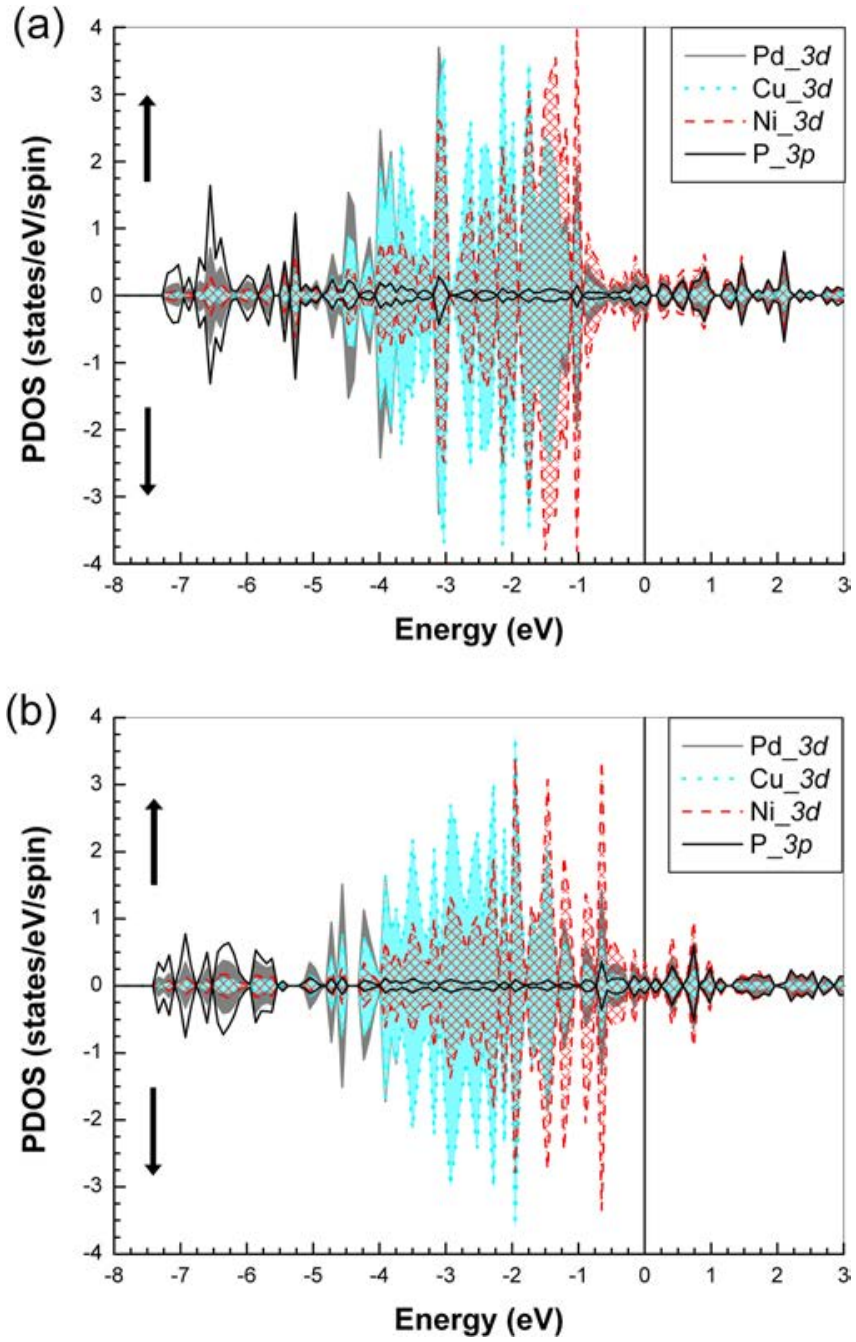

FIG. 5. (Color online) PDOS for the spin-up ( $\uparrow$ ) and spin-down $(\downarrow)$ 3d electrons for Pd (gray solid line and dark filled square), $\mathrm{Cu}$ (light blue dotted line and filled square) and $\mathrm{Ni}$ (red dashed line and crossed square) and $3 \mathrm{p}$ electron $\mathrm{P}$ (black solid line) atoms, at $\mathrm{T}=950 \mathrm{~K}$ (a) and at $\mathrm{T}=550 \mathrm{~K}$ (b), respectively. The Fermi level (vertical line) has been chosen as zero energy.

Significant structural changes in metallic glasses in the supercooled liquid state have been also observed in $\mathrm{Ti}_{39.5} \mathrm{Zr}_{39.5} \mathrm{Ni}_{21}$ liquid ${ }^{45}$ and predicted in $\mathrm{Cu}-\mathrm{Zr}$-Al glasses by $\mathrm{MD}$ computer simulation. ${ }^{46} \mathrm{~A}$ link between the structure and viscosity of $\mathrm{Cu}_{64} \mathrm{Zr}_{36}$ alloy was also suggested in $\mathrm{Ref}^{47}$.

Although the theory of the viscosity of liquids ${ }^{48}$ is still insufficiently developed, the following relationship was proposed $^{49}$ for the viscosity $(\eta)$ of liquid noble gases:

$$
\eta(T, V)=\frac{\eta_{0} \sigma^{2}}{\alpha(m \varepsilon)^{1 / 2}}
$$

where $T$ is the absolute temperature, $\varepsilon$ is the minimum potential energy of the atomic interactions, $\sigma$ is related the internal structure, while $\alpha$ and $\mathrm{m}$ are parameters. By using this formula viscosity is linked through $\sigma$ to internal structure of the liquid which is expressed in the present paper.

The liquid viscosity equation was also derived ${ }^{50}$ in terms of the activation energy $(\mathrm{Q})$ and molar volume $(\mathrm{V})$ :

$$
\eta=(N h / V) \exp (Q / R T)
$$

where $N$ is the Avogadro's number, $h$ is the Planck's constant and $R$ is the universal gas constant. Q and molar volume are also dependent on the structure of the liquid and support the idea that structural changes affect the viscosity.

It has been suggested earlier that the difference in two activation energies at high and low temperature, determine fragility of the liquid. ${ }^{51}$ One can suggest that structural changes in the supercooled liquid leading to the formation of atomic clusters initiate the changes in the activation energy (Q) which in term determines viscosity through Eq. (4).

Fragility of a glass-forming alloy in a supercooled liquid state was suggested to correlate with the Poisson's ratio ${ }^{52}$ in the glassy state and the amount of heat capacity change in the glass-transition region. ${ }^{40}$ It is also a sign of instability of short and medium range order in fragile liquids. As the supercooled $\mathrm{Pd}_{42.5} \mathrm{Cu}_{30} \mathrm{Ni}_{7.5} \mathrm{P}_{20}$ liquid is a fragile substance $(\mathrm{m}=60)$ its structural changes on cooling are more evident compared to strong liquids and can be monitored in the synchrotron radiation experiments. The link between the structure of the liquid and viscosity provided in the present work may indicate that other properties may also be dependent on the degree of chemical short range order.

\section{CONCLUSION}

In conclusion, $\mathrm{x}$-ray diffraction measurements during in situ vitrification of the $\mathrm{Pd}_{42.5} \mathrm{Cu}_{30} \mathrm{Ni}_{7.5} \mathrm{P}_{20}$ liquid alloy reveal atomic structural changes in the supercooled regime. The coincidence of the temperature dependence of the first subpeak intensity and that of viscosity in the supercooled liquid alloy suggests that increased CSRO due to formation of these $(\mathrm{Ni}, \mathrm{Cu})-\mathrm{P}$ clusters may be directly responsible for the rapid non-Arrhenius increase in viscosity of a supercooled liquid upon cooling and its fragile behavior. The first-principles calculations produce similar results and confirm the experimental findings. Continuous structural changes in the supercooled liquid leading to the formation of atomic clusters may change the activation energy $(\mathrm{Q})$ for viscous flow and determine fragility of the glass-forming liquids.

\section{ACKNOWLEDGMENTS}

Support from the European Network on bulk metallic glasses, the French National ANR project, an ESRF longterm project coordinated by A.R.Y., as well as by Grant-inAid "Priority Area on Science and Technology of Microwave-Induced, thermally Non-Equilibrium Reaction Field" (Grant No. N: 18070001) from MEXT, Japan, leaded by D.L., are gratefully acknowledged. D.L. addresses his gratitude to Y. Waseda and S. Suzuki (Tohoku University) for providing the computer programs used for structural analysis. T.E. was partly supported by the US Department of Energy, Basic Energy Science through contract DE-AC0500OR-22725.

${ }^{1}$ C. A. Angell, J. Non-Cryst. Solids, 131, 13 (1991).

${ }^{2}$ S. Sastry, P. G. Debenedetti, and F. H. Stillinger, Nature 393, 554 (1998).

${ }^{3}$ K. Ito, C. T. Moynihan, and C. A. Angell, Nature 398, 492 (1999). 
${ }^{4}$ A. Inoue, Acta Mater. 48, 279 (2000).

${ }^{5}$ A. L. Greer, Science 267, 1947 (1995).

${ }^{6}$ W. L. Johnson, Mater. Res. Bull. 24, 42 (1999).

${ }^{7}$ H. S. Chen, Acta Metall. 22, 1505 (1974).

${ }^{8}$ N. Nishiyama and A. Inoue, Appl. Phys. Lett. 80, 568 (2002).

${ }^{9}$ I. R. Lu, G. Wilde, G. P. Görler, and R. Willnecker, J. Non-Cryst. Solids 250, 577 (1999).

${ }^{10}$ N. Chen, D. V. Louzguine-Luzgin, G. Q. Xie, T. Wada, and A. Inoue, Acta Mater. 57, 2775 (2009)

${ }^{11}$ T. Egami, W. Dmowski, Y. He, and R. B. Schwarz, Metall. Mater. Trans. A 29, 1805 (1998).

${ }^{12}$ Y. Waseda, H. S. Chen, K. T. Jacob, and H. Shibata, Sci. Technol. Adv. Mater. 9, 023003 (2008).

${ }^{13}$ S. Hosokawa, J. F. Berar, N. Boudet, T. Ichitsubo, E. Matsubara, W. C. Pilgrim, and N. Nishiyama, J. Phys.: Conf. Ser. 98, 012013 (2008).

${ }^{14}$ N. Mattern, H. Hermann, S. Roth, J. Sakowski, M. P. Macht, P. Jovari, and J. Jiang, Appl. Phys. Lett. 82, 2589 (2003).

${ }^{15}$ D. V. Louzguine-Luzgin and A. Inoue, J. Nanosci. Nanotechnol. 5, 999 (2005).

${ }^{16}$ L. Hennet, I. Pozdnyakova, A. Bytchkov, D. L. Price, G. N. Greaves, M. Wilding, S. Fearn, C. M. Martin, D. Thiaudière, J.-F. Bérar, N. Boudet, and M. L. Saboungi, J. Chem. Phys. 126, 074906 (2007).

${ }^{17}$ A. R. Yavari, A. Le Moulec, A. Inoue, N. Nishiyama, N. Lupu, E. Matsubara, W. J. Botta, G. Vaughan, M. Di Michiel, and A. Kvick, Acta Mater. 53, 1611 (2005).

${ }^{18}$ K. Georgarakis, D. V. Louzguine-Luzgin, J. Antonowicz, G. Vaughan, A. R. Yavari, T. Egami, and A. Inoue, Acta Mater. 59, 708 (2011).

${ }^{19}$ Q. K. Jiang, Z. Y. Chang, X. D. Wang, and J. Z. Jiang, Metall. Mater. Trans. A 41A, 1634 (2010)

${ }^{20}$ D. V. Louzguine, A. R. Yavari, K. Ota, G. Vaughan, and A. Inoue, J. NonCryst. Solids 351, 1639 (2005).

${ }^{21}$ P. H. Gaskell, J. Non-Cryst. Solids 351, 1003 (2005).

${ }^{22}$ H. W. Sheng, W. K. Luo, F. M. Alamgir, J. M. Bai and E. Ma, Nature 439, 419 (2006)

${ }^{23}$ D. V. Louzguine-Luzgin, J. Antonowicz, K. Georgarakis, G. Vaughan, A. R. Yavari, and A. Inoue, J. Alloys Compd. 466, 106 (2008).

${ }^{24}$ R. Bohmer, K. L. Ngai, C. A. Angell, and D. J. Plazek, J. Chem. Phys. 99, 4201 (1993).

${ }^{25}$ G. J. Fan, J. F. Löffler, R. K. Wunderlich, and H. J. Fecht, Acta Mater. 52, 667 (2004).
${ }^{26}$ Y. Waseda, The Structure of Non-Crystalline Materials, Liquids and Amorphous Solids (McGraw-Hill, New York, 1980), p. 670.

${ }^{27}$ P. J. Chupas, X. Y. Qiu, J. C. Hanson, P. L. Lee, C. P. Grey, and S. J. L. Billinge, J. Appl. Cryst. 36, 1342 (2003).

${ }^{28}$ R. Tarumi, N. Hayama, M. Hirao, Y. Higo, H. Kimura, and A. Inoue, Jpn. J. of Appl Phys. 47, 3807 (2008).

${ }^{29}$ G. Kresse and J. Furthmuller, Phys. Rev. B 54, 011169 (1996).

${ }^{30}$ G. Kresse and J. Furthmuller, Mater. Sci. 6, 15 (1996).

${ }^{31}$ J. P. Perdew, K. Burke, and M. Ernzerhof, Phys. Rev. Lett. 77, 3865 (1996).

${ }^{32}$ P. E. Blöchl, Phys. Rev. B 50, 17953 (1994).

${ }^{33}$ O. N. Senkov and D. B. Miracle, Mater. Res. Bull. 36, 2183 (2001).

${ }^{34}$ B. H. Toby and T. Egami, Acta Cryst. A 48, 336 (1992).

${ }^{35}$ D. V. Louzguine-Luzgin, A. Inoue, A. R. Yavari, and G. Vaughan, Appl. Phys. Lett. 88, 121926 (2006).

${ }^{36}$ D. V. Louzguine-Luzgin and A. Inoue, Physica B 388, 290 (2007)

${ }^{37}$ D. V. Louzguine-Luzgin, J. Antonowicz, K. Georgarakis, G. Vaughan, A. R. Yavari, and A. Inoue, J. Alloys Compd. 466, 106 (2008).

${ }^{38}$ H. Kato, T. Wada, M. Hasegawa, J. Saida, A. Inoue, and H. S. Chen, Scr. Mater. 54, 2023 (2006).

${ }^{39}$ R. Busch and W. L. Johnson, Appl. Phys. Lett. 72, 2695 (1998).

${ }^{40}$ C. A. Angell, Science 267, 1924 (1995).

${ }^{41}$ R. Messmer, Phys. Rev. B 23, 1616 (1981).

${ }^{42}$ P. H. Gaskell, Nature 276, 484 (1978).

${ }^{43}$ H. W. Sheng, W. K. Luo, F. M. Alamgir, J. M. Bai, and E. Ma, Nature 439, 419 (2006)

${ }^{44}$ T. Egami, Mater. Trans. 43, 510 (2002).

${ }^{45}$ K. F. Kelton, G. W. Lee, A. K. Gangopadhyay, R. W. Hyers, T. J. Rathz, J. R. Rogers, M. B. Robinson, and D. S. Robinson, Phys. Rev. Lett. 90, 195504 (2003).

${ }^{46}$ Y. Q. Cheng, E. Ma, and H. W. Sheng, Appl. Phys. Lett. 93, 111913 (2008).

${ }^{47}$ N. Jakse and A. Pasturel, Appl. Phys. Lett. 93, 113104 (2008).

${ }^{48}$ S. G. Brush, Chem. Rev. 62, 513 (1962).

${ }^{49}$ M. J. Tham and K. E. Gubbins, Ind. Eng. Chem. Fundam. 9(1), 63 (1970).

${ }^{50}$ D. S. Visthwanah, T. K. Ghosh, D. H. L. Prasad, N. K. Dutt, and K. Y. Rani, Viscosity of Liquids Theory, Estimation, Experiment, and Data (Springer, Dordrecht, The Netherlands, 2007) p. 643.

${ }^{51}$ M. I. Ojovan and W. E. Lee, J. Appl. Phys. 95, 3803 (2004).

${ }^{52}$ V. N. Novikov and A. P. Sokolov, Nature 431, 961 (2004). 